\title{
Social workers' involvement in advance care planning: a systematic narrative review
}

Chong-Wen Wang ${ }^{1,2}$ (D) Cecilia L. W. Chan ${ }^{1,2,3}$ and Amy Y. M. Chow ${ }^{1,3^{*}}$

\begin{abstract}
Background: Advance care planning is a process of discussion that enables competent adults to express their wishes about end-of-life care through periods of decisional incapacity. Although a number of studies have documented social workers' attitudes toward, knowledge about, and involvement in advance care planning, the information is fragmented. The purpose of this review was to provide a narrative synthesis of evidence on social workers' perspectives and experiences regarding implementation of advance care planning.

Methods: Six databases were searched for peer-reviewed research papers from their respective inception through December 2016. All of the resulting studies relevant to both advance care planning and social worker were examined. The findings of relevant studies were synthesized thematically.

Results: Thirty-one articles met the eligibility criteria. Six research themes were identified: social workers' attitudes toward advance care planning; social workers' knowledge, education and training regarding advance care planning; social workers' involvement in advance care planning; social workers' perceptions of their roles; ethical issues relevant to advance care planning; and the effect of social work intervention on advance care planning engagement. The findings suggest that there is a consensus among social workers that advance care planning is their duty and responsibility and that social workers play an important role in promoting and implementing advance care planning through an array of activities.
\end{abstract}

Conclusions: This study provides useful knowledge for implementing advance care planning through illustrating social workers' perspectives and experiences. Further studies are warranted to understand the complexity inherent in social workers' involvement in advance care planning for different life-limiting illnesses or within different socio-cultural contexts.

Keywords: Advance care planning, Advance directive, End-of-life care, Social work, Systematic review

\section{Background}

With population aging and extended life expectancy, end-of-life (EoL) care is becoming increasingly a public health or health system problem [1,2]. Given the fact that terminally-ill persons not only suffer from physical problems but also face the problems associated with psychological, social, spiritual, and financial concerns, an interdisciplinary care approach is often applied. Social workers in varied care settings are often the key professionals who interface with patients and their families

\footnotetext{
* Correspondence: chowamy@hku.hk

'Jockey Club End-of-Life Community Care Project, Faculty of Social Sciences,

The University of Hong Kong, Hong Kong SAR, China

${ }^{3}$ Department of Social Work and Social Administration, Faculty of Social

Sciences, The University of Hong Kong, Hong Kong SAR, China

Full list of author information is available at the end of the article
}

during life transitions because of their skills of communication, negotiation, support and advocacy [3]. Social work practice is founded on a holistic model which embraces all areas of need [4]. The involvement of social workers is critical to EoL care provision [5-7].

Generally, social workers work with dying persons and their families in three major aspects: they are called upon to address psychosocial and spiritual concerns of dying persons and their families, to help the dying persons make advance care planning (ACP) or formulate advance directives (ADs), and to provide grief counselling for pre-bereaved or bereaved family members [6]. Usually, social workers are well-trained or educated in the areas of psycho-socio-spiritual intervention and grief counseling, even if they are not involved in EoL care 
practice. What are less presented in social work curriculum in most countries and thus remain uncertain for many social workers may be ACP procedures and associated issues, although educational programs on death and dying or EoL care in general may be provided to them $[4,5,8,9]$.

$\mathrm{ACP}$ is a voluntary process of discussion that extends the rights of competent adults and enables them to express or communicate their wishes about future health care through periods of decisional incapacity $[3,10,11]$. During this process, ADs may or may not be formulated, which are "a person's verbal or written expression or instructions about his or her wishes, preferences, or plans for future medical treatments or health care, in the event that he/she becomes unable to communicate" $[3,10]$. The role of ADs is to enable health care professionals to legally or ethically ascertain patients' preferences for care, so as to protect their rights and promote their quality of life and quality of death. Common elements of ACP or ADs include living wills, health care proxy (HCP) or durable power of attorney, refusal to unwanted invasive treatments, preferred priority of care, and preferred place of care. ACP allows patients to retain control over any life-prolonging treatments they may receive in the situation that they are incapable to speak for themselves [12]. The effectiveness of ACP has been studied among various older people at different care settings using different outcome measures. There is evidence that ACP positively impacts the quality of EoL care. A systematic review of 113 studies suggested that $\mathrm{ACP}$ interventions decreased life-sustaining treatment (LST), increased use of hospice and palliative care, prevented hospitalization, and increased compliance with patients' end-of-life wishes [13]. Another systematic review indicated that ACP decreased hospitalization rate of nursing home residents by 9-26\% and increased the number of residents dying in their nursing homes by 29-40\% [14]. Moreover, ACP increased the completion of ADs, concordance between preferences for care and delivered care, and likelihood of improvement of other outcomes for patients and their loved ones [15].

ACP throughout the end of life is an important facet of professional social work practice with older patients and their families, since social workers have a greater degree of familiarity with their clients' wishes and needs than other health professionals [3, 16, 17]. Moreover, social work is committed to respecting, valuing, and empowering patients [4]. A number of studies have documented social workers' attitudes toward, knowledge of, and involvement in ACP. However, the information is fragmented. To date, the literature lacks a systematic review of the findings of relevant studies in this field. To inform evidence-based social work practice, professional social work education, and healthcare or social care policy making, as well as to identify areas for future scientific studies, an examination of the findings generated from empirical or scientific research with regard to social workers' contribution in this area seems necessary. Given that EoL care is being included in the global health agenda [18], such effort may have important implications for the development of social work practice in the delivery of quality EoL care in those countries where EoL care services are underdeveloped. Thus, the purpose of this review was to provide a systematic narrative synthesis of the findings reported in peer-reviewed publications that examined social workers' perspectives and experiences regarding the implementation of ACP for older persons, so as to better understand social workers' contribution in this field and the process of how ACP was conducted in social work practice.

\section{Methods}

\section{Eligibility criteria}

The following criteria were used for study selection. (1) Types of studies. Original studies with any study design, except case reports, were considered. That is, both quantitative and qualitative studies, both descriptive and interventional studies, both cross-sectional and longitudinal studies, and both controlled and uncontrolled studies were eligible for inclusion. In order to provide a degree of quality control in study selection, only the studies published in peer-reviewed journals or unpublished theses that had been examined by reviewers were included. Conference proceedings and the publications that were not data-driven, such as editorials, commentaries, literature reviews, and discussion documents, were excluded. (2) Types of participants. Studies that included social workers either as a whole sample or as a subsample were included. Studies that included a mixed sample of health care professionals but did not make a comparison between social workers and other care professionals were excluded. Studies focusing on dying persons, caregivers, case managers and care professionals other than social workers were excluded. (3) Types of outcomes. Studies of ACP or ADs were included. Studies of EoL care in general rather than ACP in particular were excluded. Studies of concurrently medical decision making, psychiatric advance directives, or pediatric advance care planning were excluded.

\section{The literature search}

The following electronic databases were searched from their respective inception through December 2016: PubMed/Medline, Web of Science, AMED, CINAHL, SocINDEX, and PsychINFO. The following terms were used with such a search string: (advance care planning or advance directive* or advance care directive* or advance statement* or end of life care planning or end of life 
planning or end of life decision making or do-notresuscitate order* or life-sustaining treatment or living wills or health care proxy or health care surrogate*) and (social work or social worker* or social services staff or social services professional" or social care staff or social care professional* or social care provider*). We searched the electronic databases for articles containing these terms in the title, abstract or keywords. No limits were imposed on language. The reference lists of all included studies and other archives of the located publications were handsearched for further relevant articles.

\section{Data extraction and synthesis}

All records generated through the searches were exported into EndNote. The titles and abstracts were reviewed manually. Irrelevant records were excluded according to the eligibility criteria. If a record was potentially eligible for inclusion, the full-text was retrieved for further screening. Study selection, data extraction and data synthesis were conducted by one main researcher $(C W)$ and then verified by other researchers $(\mathrm{AC}, \mathrm{CC})$. Any discrepancies were resolved by discussion. From each of the included studies, we extracted the following information onto a customized data-extraction sheet: research objective, type of study design, type of participants, sample size, and major findings. We classified the included studies into different categories according to the study design and participants. A thematic analysis or synthesis of major findings of the included studies was then performed. For the studies that had multiple themes, they were allocated into multiple groups. Where uncertainty existed, the fulltext of the article was reexamined.

\section{Results}

Our searches identified 2252 potentially relevant records, and 2169 records were removed after screening the titles and abstracts. Full reports of 83 publications were acquired and 52 papers were further excluded as they were not data-driven publications, studies on EoL care in general, studies with a mixed sample, studies irrelevant to either social worker or ACP, case reports, and duplicates. Consequently, 31 articles published between 1994 and 2016 met the eligibility criteria (Fig. 1).

Of the included studies, twenty-six were conducted in the US and the remaining five were conducted in South Korea [19, 20], Singapore [21], and Israel [22, 23], respectively. Twenty studies used cross-sectional surveys, three used qualitative interviews [24-26], and the remaining eight were interventional studies [27-34]. Sixteen descriptive studies included a sample of only social workers $[11,19,20,22,24,25,35-44]$. Of them, four included social workers recruited from hospitals, additional four included social workers from nursing homes, two included social worker students, and the remaining six included a mixed sample of social workers (Table 1). Seven descriptive studies $[21,23,26,45-48]$ included a mixed sample of multidisciplinary care professionals, in which social workers were compared with nurses and/or physicians

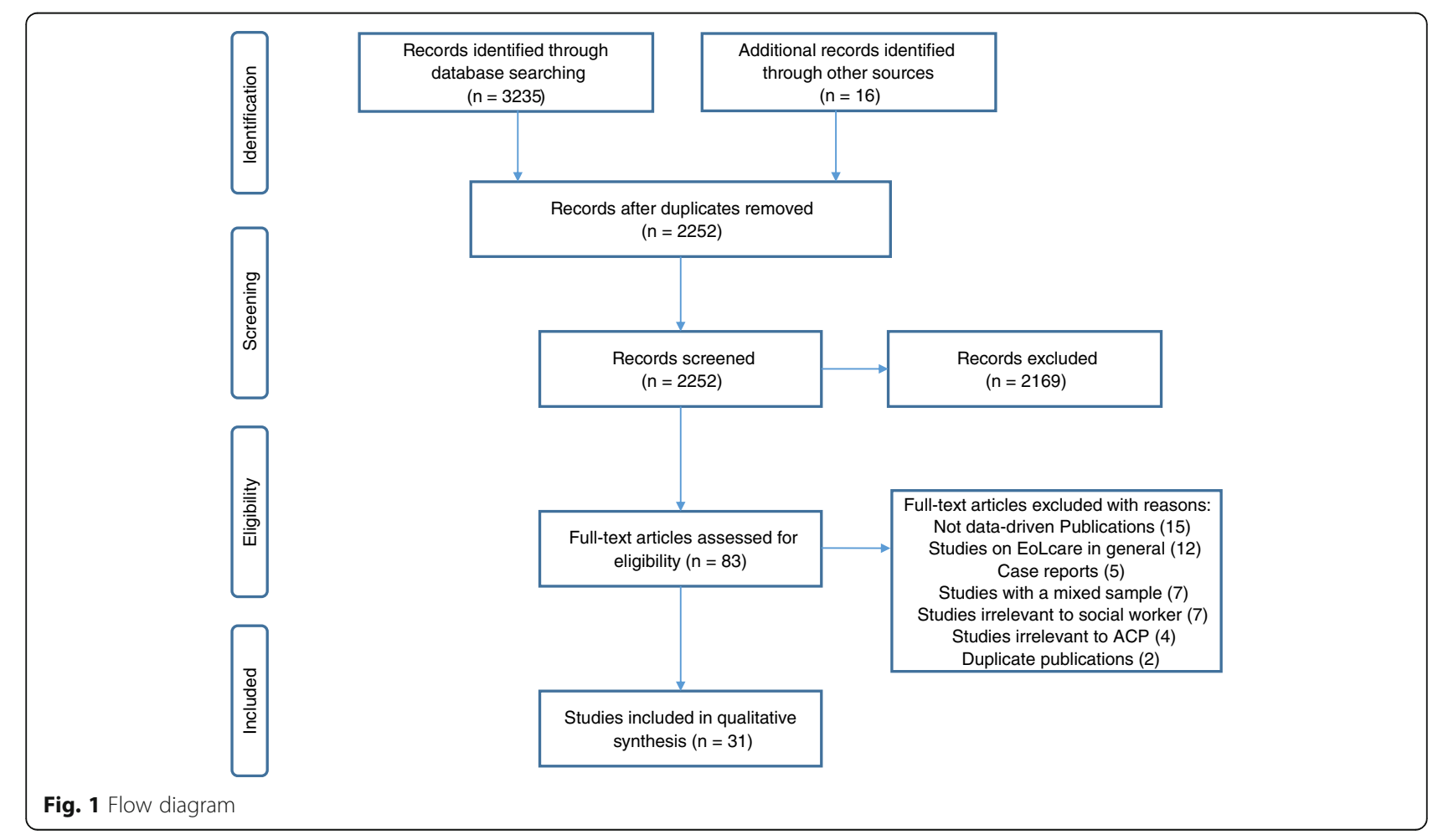




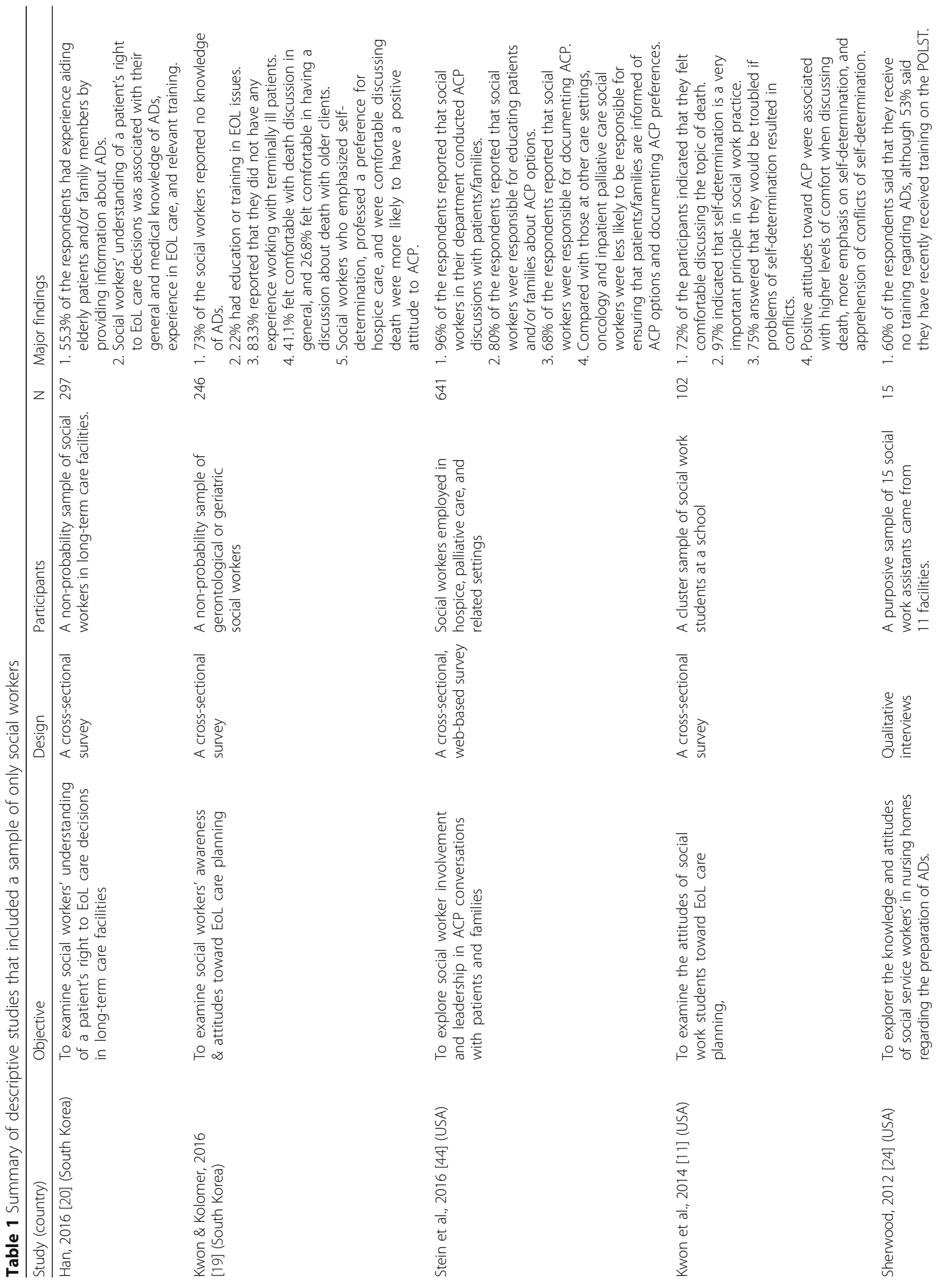




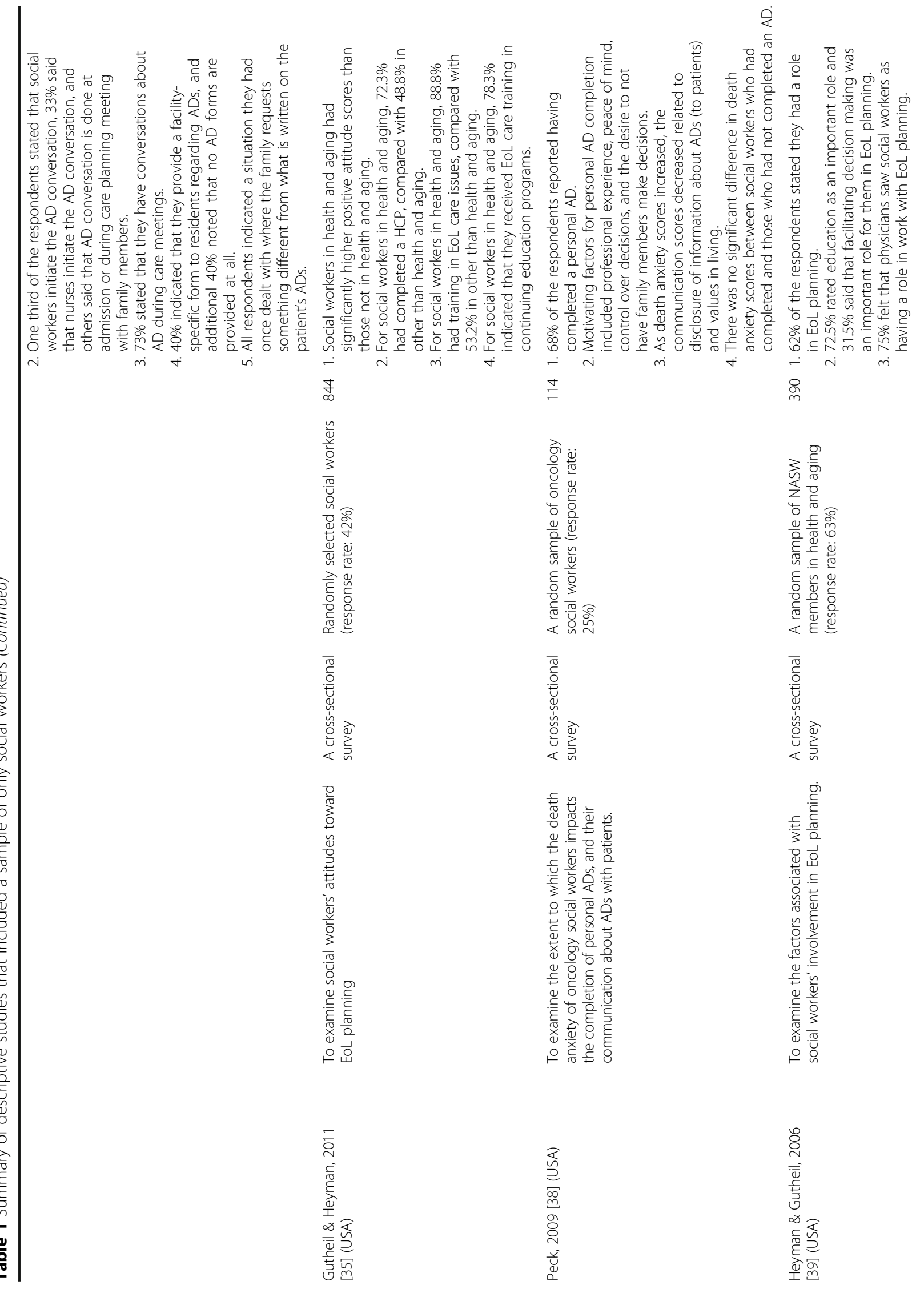




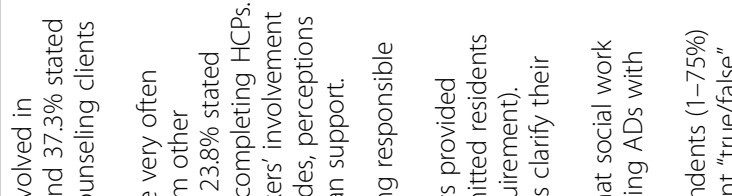

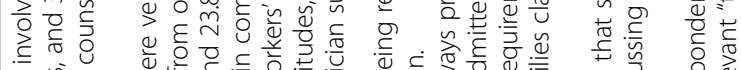

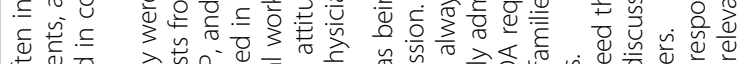

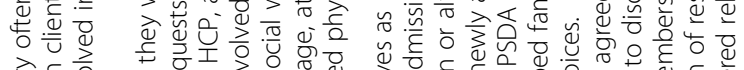

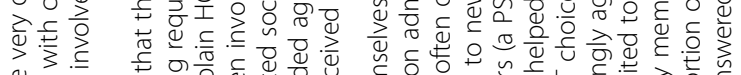

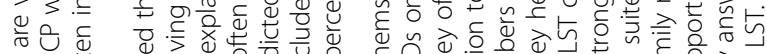

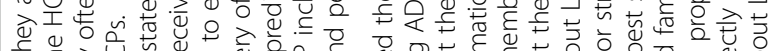

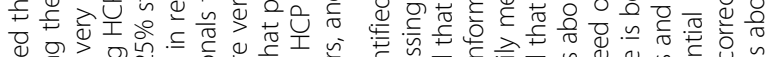

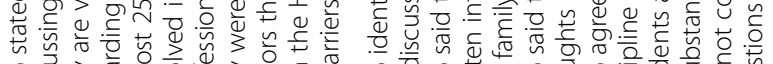

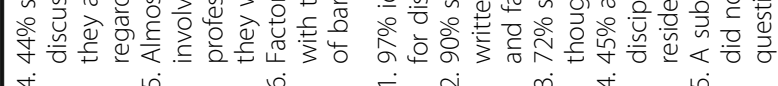

$\stackrel{\infty}{\stackrel{\infty}{m}}$

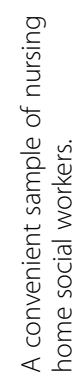

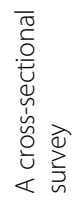

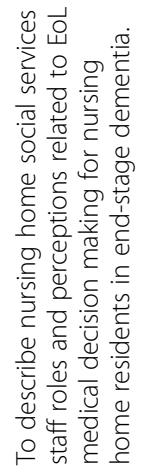

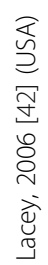
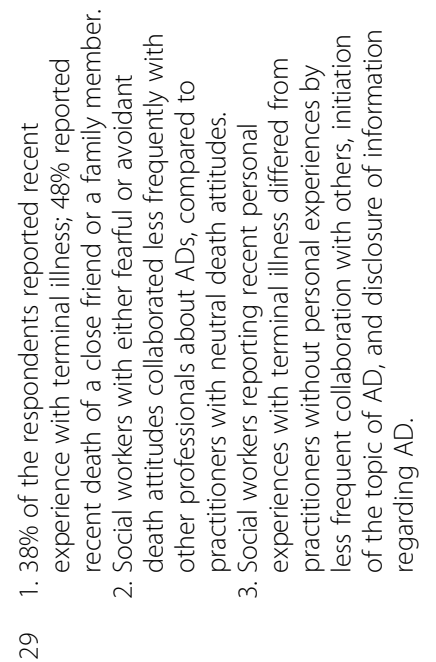

ㄱ

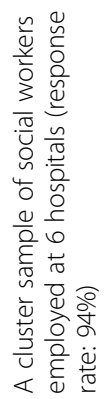

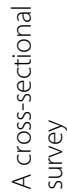

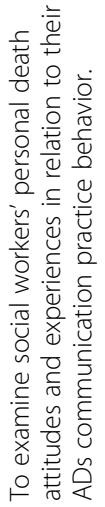

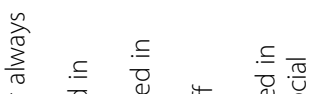

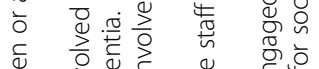

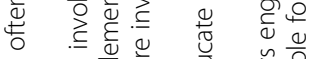

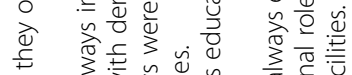

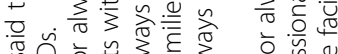

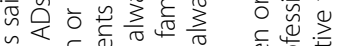

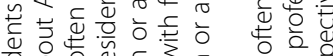

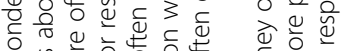

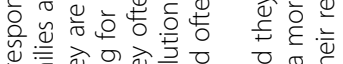

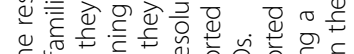

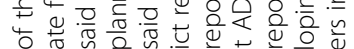

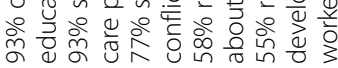

$\stackrel{\infty}{m}$

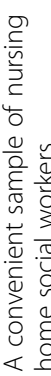

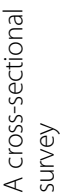

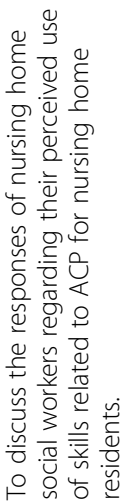

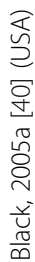

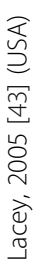


Wang et al. BMC Palliative Care (2018) 17:5

Page 7 of 20

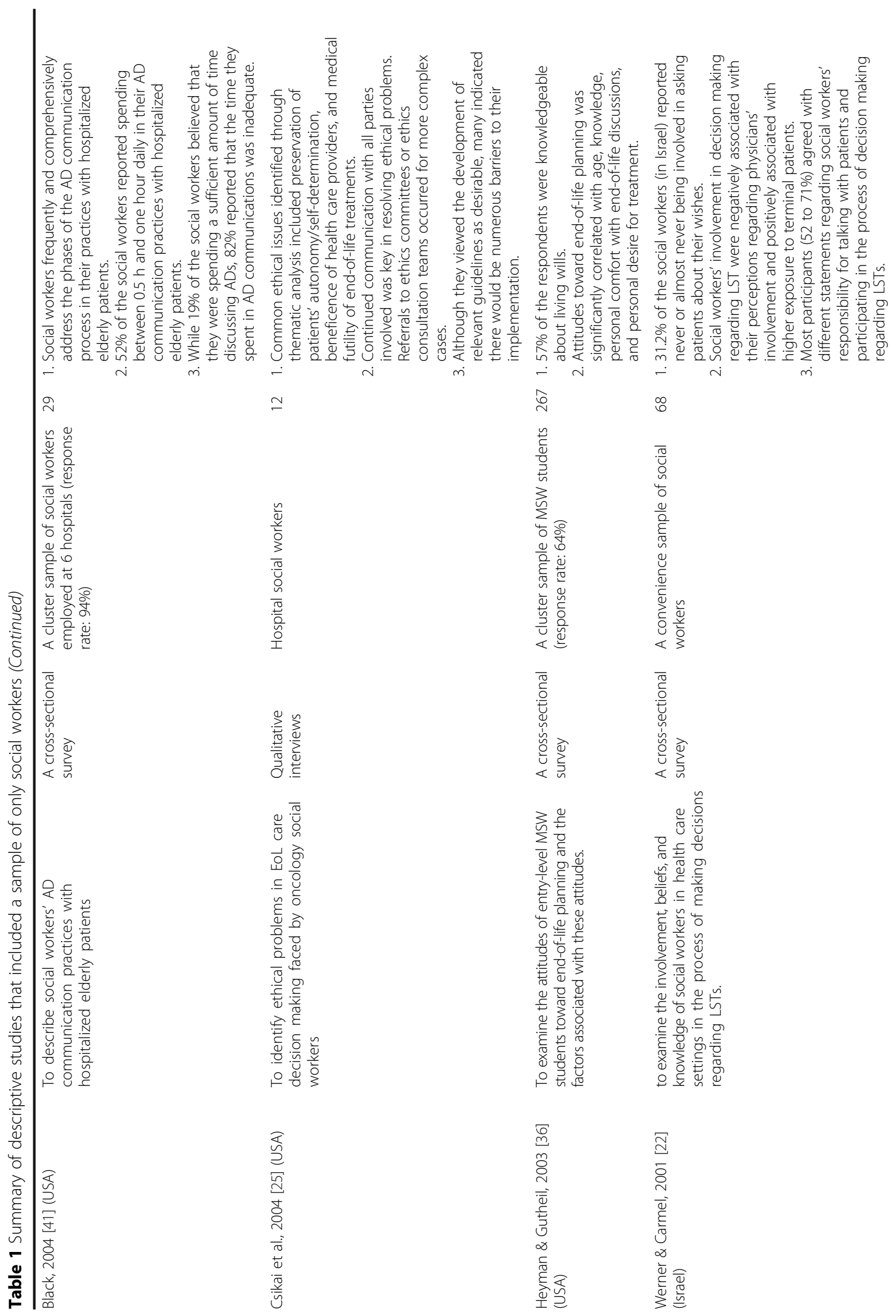


Wang et al. BMC Palliative Care (2018) 17:5

Page 8 of 20

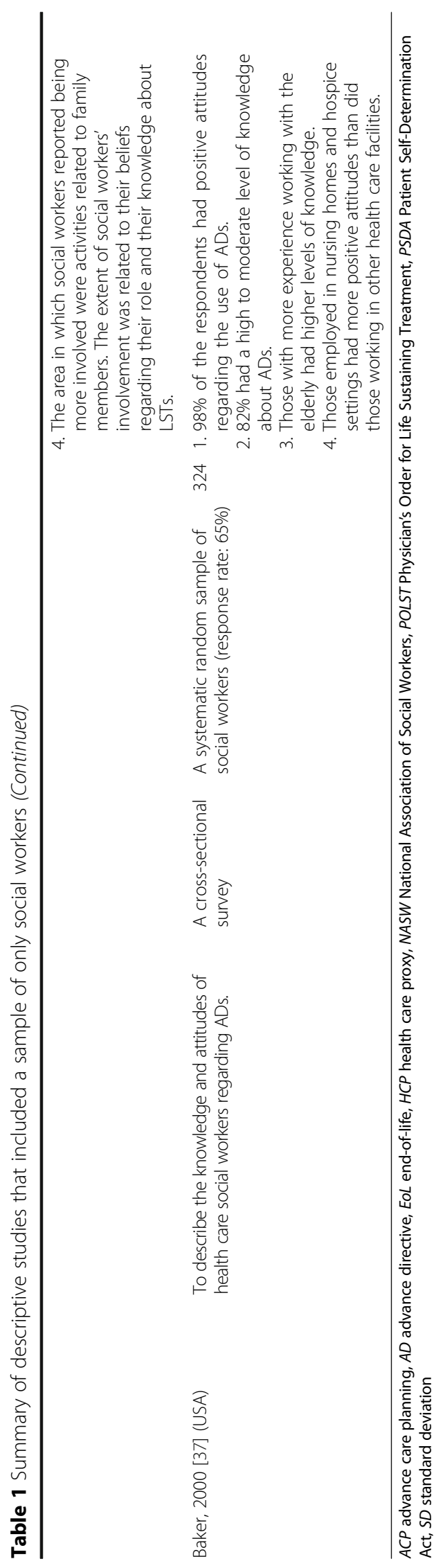


(Table 2). In the eight interventional studies, including three randomized controlled trials, one retrospective cohort study, one quasi-experimental study and three uncontrolled studies, the ACP interventions were implemented or facilitated by social workers, whilst the patients or residents were employed for outcome assessment (Table 3). The participants included adult orthopedic surgical patients who were admitted to a hospital for hip or knee replacement surgery, veteran patients recruited at different settings, newly admitted long-term care residents, outpatients, and homeless persons. Sample sizes in the included quantitative studies ranged from 10 to 13,913 , with a median of 171 . Sample sizes in the included qualitative studies ranged from 11 to 15 .

Research themes emerged in these studies varied greatly, including social workers' awareness of, knowledge about, attitudes toward, and involvement in ACP, ACP communication, beliefs and decision making about life-sustaining treatments, ethical issues related to EoL decision making, and the effect of social work intervention on ACP engagement. The findings of these studies could be classified into six categories (Table 4).

\section{Social workers' perceptions and attitudes toward ACP}

Most social workers had positive attitudes toward ACP, which varied across studies or with particular tasks. Social workers who were working in health and aging areas were more likely to have positive attitudes than those working in other areas. The attitudes toward ACP were significantly correlated with age, knowledge, personal comfort with death discussions, personal value regarding self-determination, and personal desire/preference for relevant treatments $[11,19,36]$. The attitudes toward $\mathrm{HCP}$ were associated with their perception of individual/ family barriers, perception of system barriers, and training in EoL planning [45]. Compared with those in the US, fewer social workers in South Korea felt comfortable with death discussion $[11,19]$.

\section{Social workers' knowledge, education, and training regarding $A D s$ or $A C P$}

Most social workers in the US had good knowledge about ADs, especially among those with more experience working with the elderly or in health care area [35-37]. A study indicated that $89 \%$ of health care social workers had training in EoL care issues [35], but another study reported that $60 \%$ of social workers in nursing homes received no training regarding ADs [24]. Usually, they received EoL care training in continuing education programs [35]. Their knowledge regarding life-sustaining treatments seemed to be insufficient [42]. Compared with nurses and physicians, fewer social workers reported satisfaction with $\mathrm{AD}$ laws and systems [47]. Unlike those in the US, most social workers in South Korea didn't receive education or training regarding ACP [19].

\section{Social workers' involvement in ACP discussion}

An earlier study indicated that $31 \%$ of social workers in the US were never or almost never involved in asking patients about their wishes [22], but later studies suggested that over $90 \%$ of health care social workers were involved in ACP practice, mainly at admission to care settings or in long-term care facilities [42-44], even though only one-third of social workers stated that they initiated ACP conversations [24].The majority of social workers (73\%) had conversations about ADs during care meetings [24]. They were often involved in educating patients and/or families about ACP options, providing information about $\mathrm{ACP}$, and documenting ADs [20, 42-44, 48]. A facility-specific form regarding ADs were routinely provided to the residents in $40 \%$ of nursing facilities [24]. Around $37-44 \%$ of social workers were often involved in discussing the HCP with clients [39]. Almost $25 \%$ of social workers were often involved in receiving requests from other professionals to explain HCP [39]. The area in which social workers reported being more involved was activities related to family members [22]. Over $64 \%$ of social workers indicated that they had direct responsibility in discussing ADs with patients' families [47]. Compared to physicians and nurses, social workers spent more time daily in their $\mathrm{AD}$ communication practice with patients, but most of them reported that the time they spent in $\mathrm{AD}$ communications was inadequate $[41,46]$. Unlike those in the US, many social workers in South Korea did not have any experience working with dying patients for ACP [19, 20].

Social workers' involvement in ACP or EoL decision making was correlated with their age, attitudes, perceptions of barriers, perceived physician support [39], and perceptions regarding physicians' involvement [22], fearful/avoidant death attitudes $[38,40]$, personal experiences with terminal illness [40], peace of mind, and control over decisions [38]. Those with one or more of these problems collaborated less frequently with other professionals about $\mathrm{ADs}$ and were less frequently to initiate the topic or disclose information regarding ACP [40]. Social workers with higher exposure to terminal patients was more likely involved in decision making regarding LST [22]. Major barriers against the completion of ADs included clients' discomfort with the topic, clients' knowledge about ADs, clients' fear, timing of discussions, and clients' belief about control over their lives [39].

\section{Social workers' perceptions of their roles}

Compared with physicians and nurses, medical social workers reported stronger beliefs regarding their role 


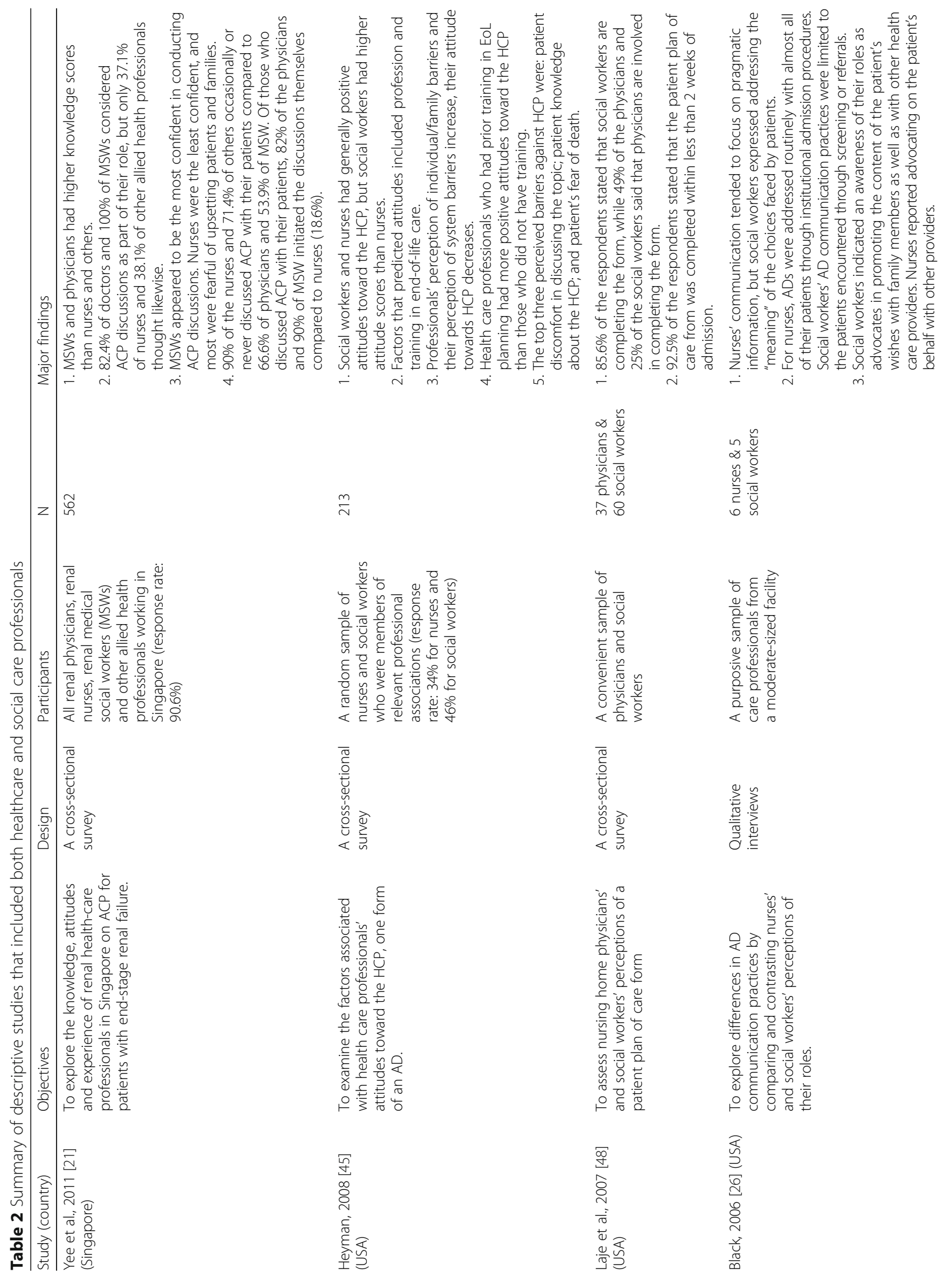




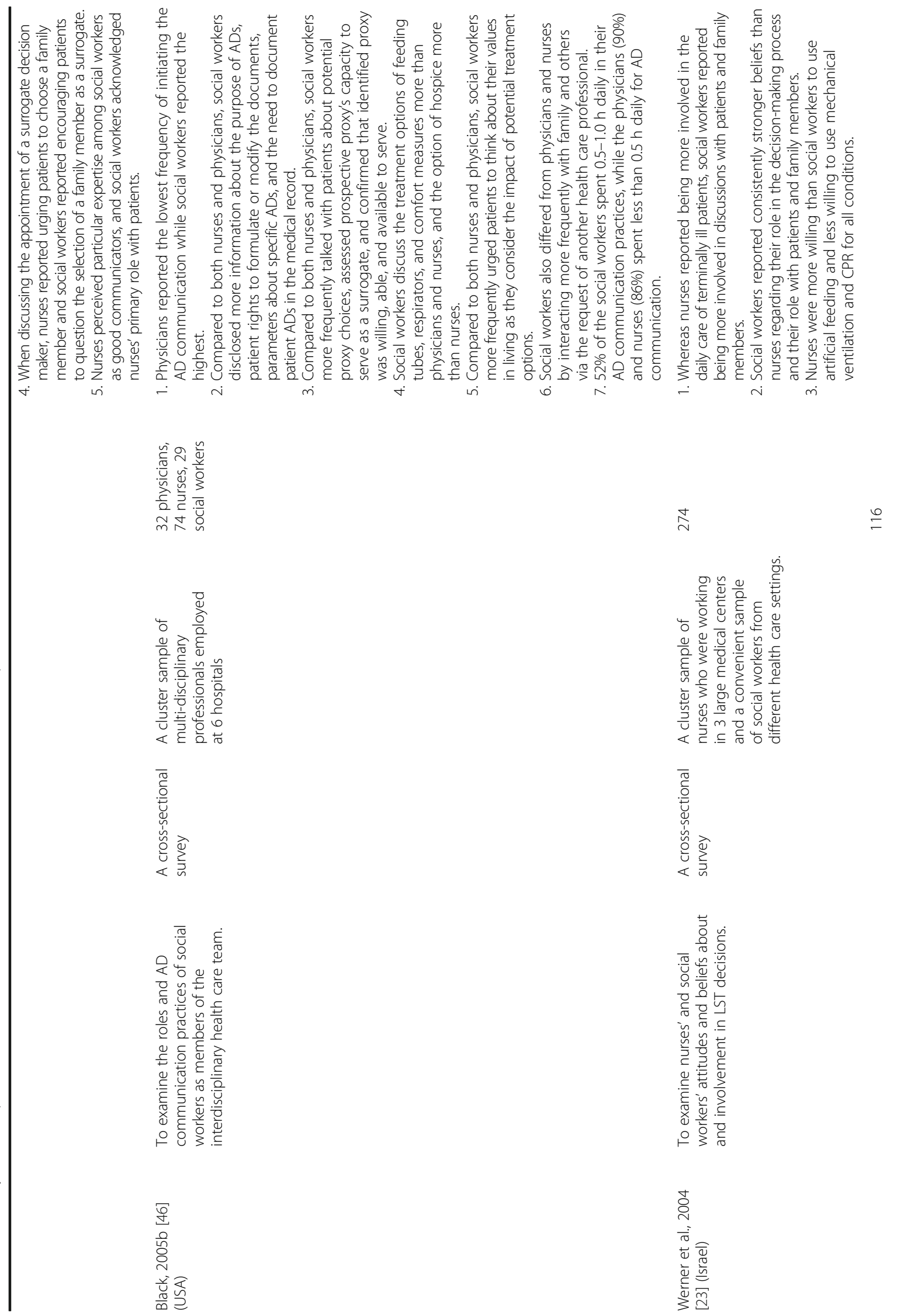




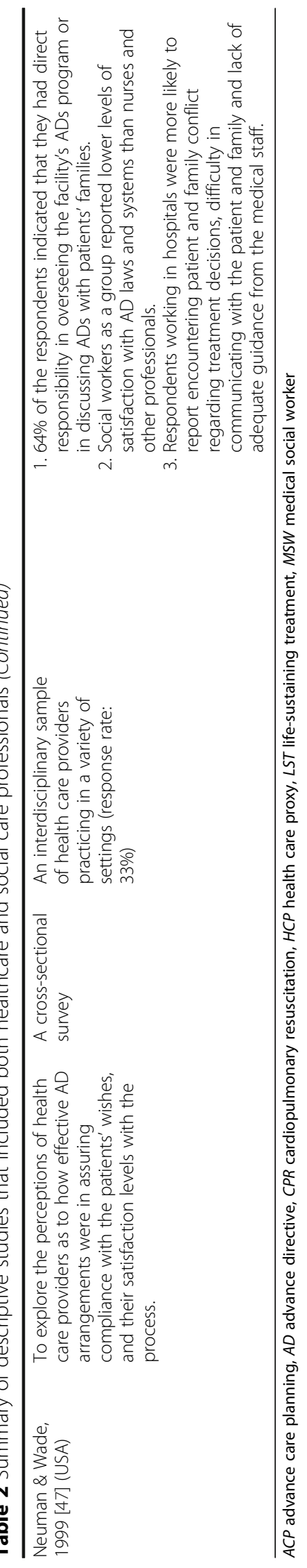




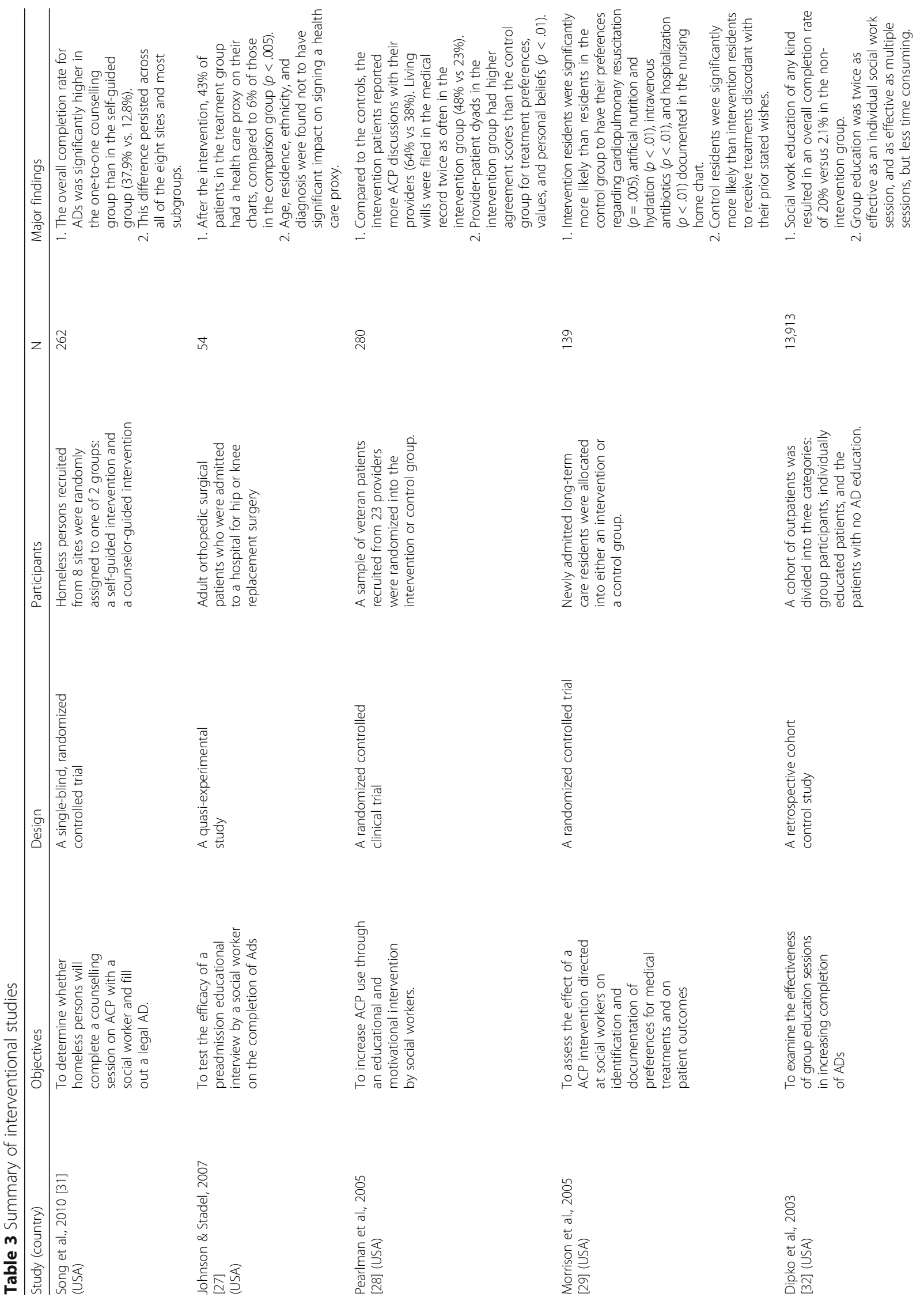




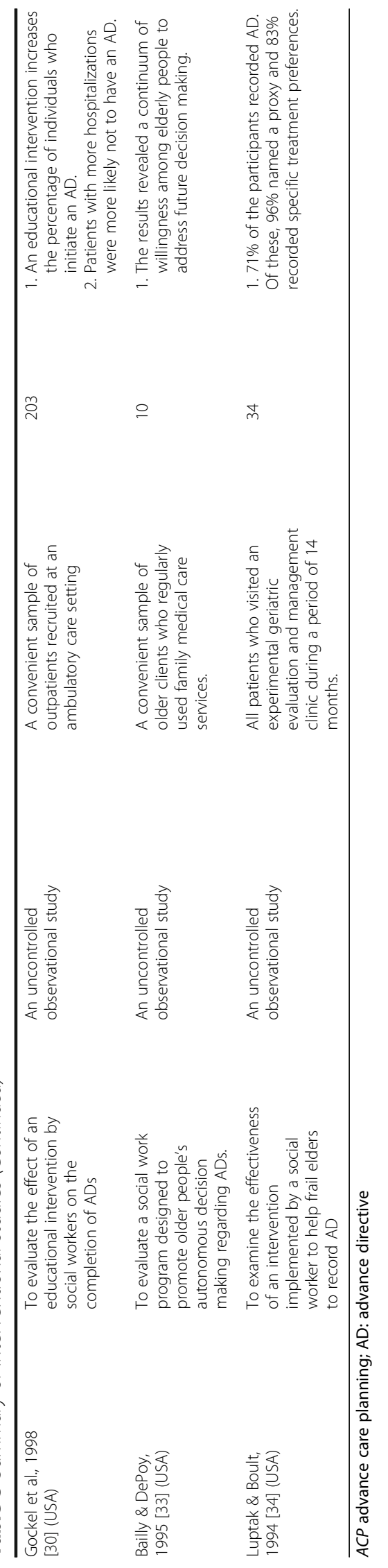


Table 4 Summary of research themes in the included studies

\begin{tabular}{ll}
\hline Themes & Major findings \\
\hline Attitudes toward the use & -98\% of social workers had positive attitudes regarding the use of ADs [37]. \\
of ACP & $97 \%$ of social workers identified themselves as being responsible for discussing ADs on admission [42]. \\
$.62 \%$ of social workers stated they had a role in EoL planning [39]. \\
$.45 \%$ of social workers agreed that social work discipline is best suited to discussing ADs with residents and \\
family members [42]. \\
$.52-71 \%$ of social workers agreed that they are responsible for talking with patients and participating in the \\
process of decision making regarding LSTs [22]. \\
$.72 \%$ of social work students in the US indicated that they felt comfortable discussing the topic of death [11]. \\
$.41 \%$ of social workers in South Korea felt comfortable with death discussion [19]. \\
. Social workers and nurses had generally positive attitudes toward the HCP, but social workers had higher attitude \\
scores than nurses [45]. \\
- Social workers in health and aging had significantly higher positive attitude scores than those not in health \\
and aging [35]. \\
- Those employed in nursing homes and hospice settings had more positive attitudes than did those working in
\end{tabular}

Knowledge, education \& training regarding $A C P$

Involvement in ACP

\section{other health care facilities [37].}

- $82 \%$ of social workers had a high to moderate level of knowledge about ADs; those with more experience working with the elderly had higher levels of knowledge [37].

- $57 \%$ of social work students were knowledgeable about living wills [36].

- For health care social workers, $88.8 \%$ had training in EoL care issues, compared with 53.2\% in other social workers, and $78.3 \%$ indicated that they received EoL care training in continuing education programs [35].

- $60 \%$ of social worker assistants said that they receive no training regarding ADs, although $53 \%$ said they have recently received training on the POLST [24].

- A substantial proportion of respondents (1-75\%) did not correctly answered relevant "true/false" questions about LST [42].

- Social workers as a group reported lower levels of satisfaction with AD laws and systems than nurses and other professionals [47].

- $73 \%$ of social workers in South Korea reported no knowledge of ADs [19].

Findings related to ADs

- $96 \%$ of the respondents reported that social workers in their department are conducting ACP discussions with patients/families [44].

- $80 \%$ of the respondents reported that social workers are responsible for educating patients and/or families about ACP options [44].

- $93 \%$ of social workers said they often or always educate families about ADs [43].

- $68 \%$ of the respondents reported that social workers are responsible for documenting ACP [44].

- $85.6 \%$ of the respondents stated that social workers are completing the care plan form, while $49 \%$ of the physicians and $25 \%$ of the social workers said that physicians are involved in completing the care plan form [48].

- $90 \%$ of social workers said that they often or always provided written information regarding ADs to newly admitted residents and family members (a PSDA requirement) [42].

- $93 \%$ of social workers said they are often or always involved in care planning for residents with dementia [43].

- One third of social workers stated that they initiate the AD conversation, 33\% said that nurses initiate the AD conversation, and others said that AD conversation is done at admission or during care planning meeting [24].

- $73 \%$ of social worker assistants stated that they have conversations about AD during care meetings [24].

- 31.2\% of social workers reported never or almost never being involved in asking patients about their wishes [22].

- $40 \%$ of social workers indicated that they provide a facility-specific form to residents regarding ADs, and additional $40 \%$ noted that no AD forms are provided at all [24].

- 55.3\% of the social workers (in South Korea) had experience aiding elderly patients and/or family members by providing information about ADs [20].

- $83.3 \%$ of the social workers (in South Korea) reported that they did not have any experience working with terminally ill patients; only $2.8 \%$ reported that they had ever provided AD planning [19].

- The area in which social workers reported being more involved was activities related to family members [22].

- $64 \%$ of social workers indicated that they had direct responsibility in discussing ADs with patients' families [47].

- $52 \%$ of social workers reported spending $0.5-1 \mathrm{~h}$ daily in their AD communication practices with hospitalized elderly patients and their families, and $82 \%$ of them reported that the time they spent in AD communications was inadequate [41].

- Compared to physicians and nurses, social workers spent more time daily in their AD communication practices with hospitalized elderly patients [46].

Findings related to HCP

- $72.3 \%$ of health care social workers had completed a HCP, compared with $48.8 \%$ of other social workers [35].

- $44 \%$ of social workers stated they are very often involved in discussing the HCP with clients, and $37.3 \%$ are very often involved in counseling clients regarding HCPs [39].

- Almost $25 \%$ of social workers stated that they were very often involved in receiving requests from other professionals to explain HCP, and 23.8\% stated they were very often involved in completing HCPs [39].

- $100 \%$ of MSWs and $82.4 \%$ of doctors considered ACP discussions as part of their role, but only $37.1 \%$ of nurses thought likewise [21]. 
Table 4 Summary of research themes in the included studies (Continued)

Social workers' roles in interdisciplinary health care teams
- $72.5 \%$ of social workers rated education as an important role and 31.5\% said that facilitating decision making was an important role for them in EoL planning [39]

- In Singapore, 53.9\% of MSWs occasionally or never discussed ACP with their patients compared to $66.6 \%$ of physicians and $90 \%$ of the nurses. Of those who discussed ACP with their patients, $90 \%$ of MSWs and $82 \%$ of the physicians initiated the discussions themselves compared to $18.6 \%$ of nurses [21].

- Social workers reported consistently stronger beliefs than nurses regarding their role with patients and family members in the decision-making process [23].

- Compared with physicians and nurses, MSWs appeared to be the most confident in conducting ACP discussions [21].

- Nurses acknowledged particular expertise among social workers as good communicators, and social workers perceived nurses' primary role with patient [26].

- Social workers reported being more involved in discussions with patients and family members, whereas nurses reported being more involved in the daily care of terminally ill patients [23].

- For nurses, ADs were addressed routinely with almost all of their patients through institutional admission procedures and routine nursing care. Social workers' AD communication practices were limited to patients encountered through screening or referrals that typically did not originate for ACP purposes [26].

- Social workers indicated an awareness of their roles as advocates in promoting the content of the patient's wishes with family members and health care providers [26].

Ethical issues related to the use of ACP
- $97 \%$ of social worker students indicated that self-determination is a very important principle in social work practice [11].

- $75 \%$ of social worker students answered that they would be troubled if problems of self-determination resulted in conflicts [11].

- 77\% of social workers said they often or always were involved in conflict resolution with families [43].

- Nearly all respondents indicated a situation they had once dealt with where the family requests something different from what is written on the patient's ADs [24].

- $72 \%$ of social workers reported that they helped families clarify their thoughts about LST choices [42]

- Common ethical issues identified through thematic analysis included preservation of patients' autonomy/selfdetermination, beneficence of health care providers, and medical futility of end-of-life treatments [25].

- Social workers working in hospitals were more likely to report encountering patient and family conflict regarding treatment decisions, difficulty in communicating with the patient and family and lack of adequate guidance from the medical staff [47].

- Continued communication with all parties involved was key in resolving ethical problems [25].

$A C P$ advance care planning, $A D$ advance directive, $H C P$ health care proxy, $L S T$ life-sustaining treatment, MSWs medical social workers, $P O L S T$ physician's order for life-sustaining treatment

with patients and family members in the decisionmaking process [23]; they appeared to be the most confident in conducting ACP discussions [21]. In a study, $100 \%$ of medical social workers considered ACP discussion as part of their role, but only $37.1 \%$ of nurses and $82.4 \%$ of doctors thought likewise [21]. Most social workers $(72.5 \%)$ rated education as an important role and $31.5 \%$ said that facilitating decision making was an important role for them in EoL planning [39]. Usually, social workers discussed ACP with their patients more frequently than physicians and nurses [21]. A study noted that social workers reported the highest frequency of initiating the topics about ADs while physicians reported the lowest [46]. Compared with physicians and nurses, social workers more frequently discussed the options of LST and the option of hospice, and more frequently talked with patients about potential proxy choices [46]. They also differed from physicians and nurses by interacting more frequently with families and others [46]. Nurses acknowledged particular expertise among social workers as good communicators, whilst social workers perceived nurses' primary role with patients [26]. For nurses, ADs were addressed routinely with almost all of their patients through institutional admission procedures and routine nursing care. Social workers' AD communication practices were mainly limited to the patients encountered through referrals or screening that typically did not originate for ACP [26].

\section{Ethical issues related to EoL decision making}

Most social workers considered self-determination as a very important principle, and agreed that they would be troubled if problems of self-determination resulted in conflicts [11]. More than three fourths of social workers were often or always involved in conflict resolution with families [43]. A study reported that nearly all of the social workers indicated a situation they had once dealt with, where the family requests something different from what was written on the patient's ADs [24]. A majority of social workers $(72 \%)$ reported that they had helped families clarify their thoughts about LST choices [42]. Common ethical issues related to ACP practice included preservation of patients' autonomy/self-determination, beneficence of health care providers, and medical futility of end-of-life treatments [25]. Social workers working in hospitals were more likely to report encountering patient and family conflict regarding treatment decisions, difficulty in communicating with the patient and family, and lack of adequate guidance from medical professionals 
[47]. Continued communication with all parties involved was key in resolving ethical problems [25].

\section{Effectiveness of social work intervention on ACP engagement}

It was reported that social workers' involvement in ACP increased the rate of patients' $\mathrm{ACP}$ discussions with care providers [28], patients' documentation of their living wills or ADs in the medical record [28] or in the nursing home chart [29], completion rate for ADs [31, 32, 34], and the appointment of HCPs [27, 34]. Compared to controls, patients in the intervention groups had higher agreement scores for treatment preferences, values and personal beliefs [28], and were less likely to receive treatments discordant with their previously expressed wishes [29]. Age, residence, ethnicity, and diagnosis didn't have significant impact on signing a HCP [27].

\section{Discussion}

In this review, empirical or scientific findings relevant to social work practice of ACP were systematically examined and thematically synthesized. A total of thirty one studies were included. Our results provided a whole profile of social workers' attitudes toward, knowledge of, and involvement in ACP practice. The findings suggest that there is a consensus among social workers that $\mathrm{ACP}$ is their duty and responsibility and that social workers play an important role in promoting and implementing ACP through an array of duties such as initiating ACP discussions, advocating patients' rights, patient and family education or counseling, facilitating communication and conflict resolution, as well as documenting discussions or ADs.

It should be noted that most of the included studies were conducted in the US, where $45-47 \%$ of all deaths occurred in hospitals and additional 22\% (28\% for those aged over 65 years) occurred in residential care facilities in the years 2003-2005 [49]. For nursing home residents, up to two-thirds of them died in place $[43,50]$. In 2015 , there were 155,500 healthcare social workers in the US [51]. Since 1991, following the passage of the Patient Self-Determination Act, health practitioners including social workers in different organizations such as hospitals, hospices and nursing homes were mandated to inform their adult patients about their rights in making EOL care related decisions and formulating living wills or ADs [11, 52]. Given the fact that many social workers felt inadequately prepared for work in the field of practice with dying and bereaved patients [53], a national program was initiated to promote professional growth among social work leaders in the late 1990s, and various continuing education and certificate programs emerged for social work practitioners thereafter [5]. Following these programs, social work professionals in the US have made considerable progress toward improving ACP practice, as indicated by the results of the studies included in this review. However, lack of knowledge regarding $\mathrm{ACP}$ and insufficient training or education among social workers are evident in Asia countries such as South Korea [19].

Unlike in the US, social workers' roles and responsibilities in the UK are different due to the disparity in the structures of the national healthcare and social care systems and variation in the professional systems between the two countries. The introduction of advance communication related to EoL care was formalized in England and Wales through the Mental Capacity Act 2005, which became effective in 2007 [54]. In the US, social work practice focuses more often on the approaches of psychosocial intervention, whereas social workers' roles in the UK are prescribed and limited to safeguarding, assessment, care planning, empowerment and partnerships [54]. To date, empirical studies of social workers' involvement in ACP are still rare in European countries.

Of the included studies, there were large variations in the concepts of ACP and ADs. For different concepts, their contents and meaning may be significantly different. These variations make it difficult to collate and compare research results across studies. Usually, ACP is viewed as a process to clarify values, wishes, preferences, and goals regarding care. This process may not be completed following one session of discussion. It may take a period of time and include many sessions of communication or discussion. Emanuel et al. (1995) proposed five steps for an idealized process of ACP: raising the awareness, facilitating a systematic discussion, completing $\mathrm{ADs}$, reviewing $\mathrm{ADs}$ periodically, and applying $\mathrm{ADs}$ in actual circumstances [55]. Black (2000) operationalized the process into 7 phases: initiation of the topic, disclosure of information, identification of a surrogate decision-maker, discussion of treatment options, elicitation of patient values, interaction with family members, and collaboration with other care professionals. Empirical studies suggested that social workers were involved in each step and phase of ACP [40, 41, 46]. ADs or living wills are legal evidence of one's preferences regarding medical interventions at the end of life. Very often, a dying patient needs to decide whether or not to refuse a specific type of invasive life-sustaining treatment. If a patient wishes to make an $\mathrm{AD}$ to refuse a treatment, the patient may need to discuss this with a health care professional who is fully aware of his/her medical conditions and cure options as well as associated problems, and the AD must be in writing, signed and witnessed. In such a situation, roles between social worker and other health professional overlap, which may lead to confusion. As indicated in a study, most social workers do not have sufficient knowledge of life- 
sustaining treatments [42]. Although social workers may not be the right persons for documenting patients' ADs in such a situation, they can act as an educator, counselor, context interpreter, advocator, and team member $[3,56]$. Thus, it is understandable that social workers usually spend more time than physicians and nurses in their daily ACP practice with patients, but are more likely to feel that the time spent in ACP communications is inadequate [41, 46]. Apart from decisionmaking regarding life-sustaining treatment, ACP includes several other important elements such as health care proxy, preferred priorities of care, and preferred place of care. Social workers are the experts to communicate with patients and their families about these issues. Social workers can also use structured ACP tools to facilitate ACP discussions [54].

Among the included studies, there is no consensus about the time and manner to initiate ACP communications. A qualitative study indicates that social work involvement occurs most often at the request of other staff, specifically nurses [50]. Some studies suggest that there are key transitions in the disease courses whereby ACP may be particularly needed, such as hospital or nursing home admissions [16]. Sometimes, social workers may need to gain permission from a patient's physician to engage in ACP communications. Very often, the dying persons are heavily constrained in their exercise of autonomy, choice and control [4]. Moreover, different countries may have different policies or approaches to promote ACP/ADs. For example, ACP is widely promoted among healthy adults of the public in the US [57], whereas an official guideline in the UK has cautioned against a rigid and prescriptive approach in order to avoid harm to relevant persons, because the discussion my cause distress [58]. Thus, it is important for social workers to know when and how to initiate ACP communications within a particular socio-cultural context. The influence of culture on EoL care preferences has been documented elsewhere [59]. There is also evidence that clinical social work practice of EoL care in a Western form, which stresses open discussion of impending death and individualized counselling, does not meet the needs of people with different cultural backgrounds or in different nations in responding to dying and death [7].

Some of the included studies suggested insufficient knowledge of ACP among social workers and insufficient education of social work students, which might have hindered them in implementing ACP [6, 42]. Many social workers indicated that much of their knowledge of ACP and ADs come from continuing education programs [42], mainly due to the lack of EoL care content in social work textbooks and the absence of faculty trained to teach EoL care [5]. While numerous publications and books in the field of EoL care have been available, social work textbooks provide little content on EOL care in general and ACP in particular [5]. While there are courses of death and dying, there is little clinical supervision focusing on EoL care and ACP practice [50]. The lack of curricular content about ACP in educational social work programs may result in practitioners being ill-equipped to work effectively in ACP practice. Nowadays, these situations may be improved in the US, but remain to be great challenges for social work professionals in other countries where EoL care has not been included social work practice agenda until recent years. Apart from educational resources, some other factors associated with social workers' attitudes toward, knowledge of, and involvement in ACP practice, as summarized in this review, should be taken into account when promoting ACP from a social work perspective.

There are several limitations in this review. First, similar to any other systematic reviews, the keywords we employed may not have captured all relevant studies; some potentially relevant articles that are only available in other databases or in other languages may have been neglected. Second, study quality was not ranked for the included studies due to heterogeneity in study designs. Interpretation and generalization of the results should be cautious due to small sample size and nonrepresentative sample in some of the included studies. Third, most of the included studies were crosssectional surveys conducted in the US, which may limit our understanding social work practice of $\mathrm{ACP}$ in European and other countries such as Australia, where ACP medico-legalities and social work scopes of practices are different from that in the US. Lastly, the differences in social work practice of ACP communications at different care settings or for different life-limiting illnesses were not differentiated due to insufficient information. Further studies in these aspects would be meaningful. Despite these limitations, our review is the first to systematically and thematically summarize relevant findings in the field, which may have implications for professional social work education, EoL care practice, and healthcare or social care policy making.

\section{Conclusion}

On the basis of available evidence, this review provides a whole profile of social workers' attitudes toward, knowledge of, and involvement in ACP practice, mainly in the US. The findings suggest that social workers can be core members of health care teams providing EoL care, and that social workers play an important role in promoting and implementing ACP. This review provides useful information or knowledge for implementing ACP through illustrating social workers' perspectives and experiences. 
It also suggests insufficient knowledge and limited education regarding ACP among social workers, which may be major barriers for social work practice in this field. The results of this review can assist social workers, professionals, educators, and policy makers to develop policies, programs, and practical guidelines for ACP-related education and practice so as to create an appropriate environment for promoting ACP and increase the competency of social workers in EoL care practice. Where ACP is clearly legislated as an act that must be advocated for dying persons, more attention should be focused on logistics of clinical practice of ACP communications. Provision of ACP-related curriculum, educational programs and practical information for social workers, especially those in the countries or regions where EoL care services are underdeveloped, is recommended so as to increase their knowledge about ACP and conversation skills. Further research is also warranted to understand the complexity inherent in social work practice of ACP discussions or communications in formulating EOL care preferences at different care settings for different life-limiting illnesses within different socio-cultural contexts, so as to promote quality of life and well-being of dying persons and their families.

\section{Abbreviations}

ACP: Advance care planning; ADs: Advance directives; EoL: End-of-life HCP: Health care proxy; LST: Life-sustaining treatment; MSWs: Medical social workers; POLST: Physician's order for life-sustaining treatment; PSDA: Patient Self-Determination Act; UK: United Kingdom; US: United States

\section{Acknowledgements}

The authors would like to thank all members of the wider project team for their assistance and support.

\section{Funding}

None to report.

\section{Availability of data and materials}

This paper is a systematic review. Articles selected for this review were referenced in bibliography. All data extracted from the selected studies were presented in the tables.

\section{Authors' contributions}

CW designed the review, searched the literature, extracted the data, and drafted the manuscript; CC and AC contributed comments for critical revision of the manuscript. All authors read and approved the final manuscript.

\section{Ethics approval and consent to participate}

Not applicable.

\section{Consent for publication}

Not applicable.

\section{Competing interests}

The authors declared that they have no competing interests.

\section{Publisher's Note}

Springer Nature remains neutral with regard to jurisdictional claims in published maps and institutional affiliations.

\section{Author details}

Jockey Club End-of-Life Community Care Project, Faculty of Social Sciences, The University of Hong Kong, Hong Kong SAR, China. ${ }^{2}$ Centre on Behavioral Health, Faculty of Social Sciences, The University of Hong Kong, Hong Kong SAR, China. ${ }^{3}$ Department of Social Work and Social Administration, Faculty of Social Sciences, The University of Hong Kong, Hong Kong SAR, China.

Received: 23 January 2017 Accepted: 26 June 2017

Published online: 10 July 2017

\section{References}

1. United Nations: World population ageing. 2009. Retrieved from http://www. un.org/esa/population/publications/WPA2009/WPA2009_WorkingPaper.pdf

2. World Health Organization. Palliative care for older people: Better practices. 2011. Retrieved from http://www.euro.who.int/_data/assets/pdf_file/0017/ 143153/e95052.pdf.

3. Morrissey MB. Role of social workers as central health care professionals in advance care and end of life planning, and end of life decision making. J Pastor Couns. 2005;40:28-48.

4. Holloway M. Dying old in the 21st century a neglected issue for social work. Int Soc Work. 2009;52(6):713-25.

5. Murty SA, Sanders S, Stensland M. End-of-life care as a field of practice in the social work curriculum. J Soc Work End Life Palliat Care. 2015;11(1):11-26.

6. Brandsen CK. Social work and end-of-life care: reviewing the past and moving forward. J Soc Work End Life Palliat Care. 2005; (2):45-70.

7. Payne M. Developments in end-of-life and palliative care social work international issues. Int Soc Work. 2009;52(4):513-24.

8. Forrest C, Derrick C. Interdisciplinary education in end-of-life care: creating new opportunities for social work, nursing, and clinical pastoral education students. J Soc Work End Life Palliat Care. 2010;6(1-2):91-116.

9. Berzoff J, Lucas G, Deluca D, Gerbino S, Browning D, Foster Z, Chatchkes E. Clinical social work education in palliative and end-of-life care: relational approaches for advanced practitioners. J Soc Work End Life Palliat Care. 2006;2(2):45-63.

10. Aitken PV. Incorporating advance care planning into family practice. Am Fam Physician. 1999;59(3):605-14.

11. Kwon SA, Kolomer S, Alper J. The attitudes of social work students toward end-of-life care planning. J Soc Work End Life Palliat Care. 2014;10(3):240-56.

12. Fried TR, Bullock K, lannone L, O'Leary JR. Understanding advance care planning as a process of health behavior change. J Am Geriatr Soc. 2009:57(9):1547-55.

13. Brinkman-Stoppelenburg A, Rietjens JA, van der Heide A. The effects of advance care planning on end-of-life care: a systematic review. Palliat Med. 2014;28(8):1000-25.

14. Martin RS, Hayes B, Gregorevic K, Lim WK. The effects of advance care planning interventions on nursing home residents: a systematic review. J Am Med Dir Assoc. 2016;17(4):284-93.

15. Houben CH, Spruit MA, Groenen MT, Wouters EF, Janssen DJ. Efficacy of advance care planning: a systematic review and meta-analysis. J Am Med Dir Assoc. 2014;15(7):477-89.

16. Black K. Advance care planning throughout the end-of-life: focusing the lens for social work practice. J Soc Work End Life Palliat Care. 2007;3(2):39-58.

17. Chaddock R. Integrating early multi-disciplinary advance care planning into Core social work practice: social Workers'bread and butter. J Soc Work Pract. 2016;30(2):129-38.

18. Harding R, Higginson IJ. Inclusion of end-of-life care in the global health agenda. Lancet Glob Health. 2014;2(7):e375-6.

19. Kwon SA, Kolomer S. Advance care planning in South Korea: social work perspective. Soc Work Health Care. 2016;55(7):545-58.

20. Han S. The effects of South Korean social Workers'professional resources on their understanding of a Patient's right to end-of-life care decisions in long-term care facilities. Asian Soc Work Policy Rev. 2016;10(2):200-9.

21. Yee A, Seow YY, Tan SH, Goh C, Qu LM, Lee G. What do renal health-care professionals in Singapore think of advance care planning for patients with end-stage renal disease? Nephrology. 2011;16(2):232-8.

22. Werner P, Carmel S. End-of-life decision making: practices, beliefs and knowledge of social workers in health care settings. Educ Gerontol. 2001;27(5):387-98.

23. Werner P, Carmel S, Ziedenberg H. Nurses'and social workers'attitudes and beliefs about and involvement in life-sustaining treatment decisions. Health \& Social Work. 2004;29(1):27-35. 
24. Sherwood J. The preparation of advance directives in skilled nursing facilities: social service workers'knowledge and attitudes. Long Beach: California State University; 2012.

25. Csikai EL, Roth S, Moore C. Ethical problems in end-of-life care decision making faced by oncology social workers and the need for practice guidelines. J Psychosoc Oncol. 2004;22(1):1-18.

26. Black K. Advance directive communication: nurses'and social workers'perceptions of roles. Am J Hosp Palliat Care. 2006;23(3):175-84.

27. Johnson YM. Completion of advance directives: do social work preadmission interviews make a difference? Res Soc Work Pract. 2007;17(6):686-96.

28. Pearlman RA, Starks H, Cain KC, Cole WG. Improvements in advance care planning in the veterans affairs system - results of a multifaceted intervention. Arch Intern Med. 2005;165(6):667-74.

29. Morrison RS, Chichin E, Carter J, Burack O, Lantz M, Meier DE. The effect of a social work intervention to enhance advance care planning documentation in the nursing home. J Am Geriatr Soc. 2005;53(2):290-4.

30. Gockel J, Morrow-Howell N, Thompson E, Pousson M, Johnson M. Advance directives: a social work initiative to increase participation. Res Soc Work Pract. 1998;8(5):520-8.

31. Song J, Ratner ER, Wall MM, Bartels DM, Ulvestad N, Petroskas D, West M, Weber-Main AM, Grengs L, Gelberg L. Effect of an end-of-life planning intervention on the completion of advance directives in homeless persons a randomized trial. Ann Intern Med. 2010;153(2):76-W30.

32. Dipko LR, Xavier K, Kohlwes RJ. Advance directive group education in a VA outpatient clinic. Soc Work Health Care. 2003;38(2):93-106.

33. Bailly DJ, Depoy E. Older peoples responses to education about advance directives. Health \& Social Work. 1995;20(3):223-8.

34. Luptak MK, Boult C. A method for increasing elders use of advance directives. Gerontologist. 1994;34(3):409-12.

35. Gutheil IA, Heyman JC. A social work perspective: attitudes toward end-oflife planning. Soc Work Health Care. 2011;50(10):763-74.

36. Heyman JC, Gutheil IA. Attitudes of social work students toward end-of-life planning. Educ Gerontol. 2003;29(4):313-26.

37. Baker ME. Knowledge and attitudes of health care social workers regarding advance directives. Soc Work Health Care. 2000;32(2):61-74.

38. Peck MR. Personal death anxiety and communication about advance directives among oncology social workers. J Soc Work End-Life. 2009;5(1-2):49-60.

39. Heyman JC, Gutheil IA. Social work involvement in end of life planning. J Gerontol Soc Work. 2006;47(3-4):47-61.

40. Black K. Social workers'personal death attitudes, experiences, and advance directive communication behavior. J Soc Work End Life Palliat Care. 2005; 1(3):21-35

41. Black K. Advance directive communication with hospitalized elderly patients: social workers'roles and practices. J Gerontol Soc Work. 2004;43(2-3):131-45.

42. Lacey D. End-of-life decision making for nursing home residents with dementia: a survey of nursing home social services staff. Health Soc Work. 2006;31(3):189-99.

43. Lacey D. Nursing home social worker skills and end-of-life planning. Soc Work Health Care. 2005;40(4):19-40.

44. Stein GL, Cagle JG, Christ GH. Social work involvement in advance care planning: findings from a large survey of social Workers in Hospice and Palliative Care Settings. J Palliat Med. 2017;20(3):253-9.

45. Heyman JC. Social workers'and nurses'attitudes toward the health care proxy. J Soc Work End Life Palliat Care. 2008;4(1):57-74.

46. Black K. Advance directive communication practices: social workers'contributions to the interdisciplinary health care team. Soc Work Health Care. 2005;40(3):39-55

47. Neuman K, Wade L. Advance directives: the experience of health care professionals across the continuum of care. Soc Work Health Care. 1999;28(3):39-54.

48. Laje RP, Wilks GB, Marx M, Cohen-Mansfield J. The Maryland patient plan of care form: perceptions of physicians and social workers. J Am Med Dir Assoc. 2007;8(9):575-81.

49. Broad JB, Gott M, Kim H, Boyd M, Chen H, Connolly MJ. Where do people die? An international comparison of the percentage of deaths occurring in hospital and residential aged care settings in 45 populations, using published and available statistics. Int J Public Health. 2013;58(2):257-67.

50. Munn JC, Adorno G. By invitation only: social work involvement at the end of life in long-term care. J Soc Work End-Life. 2008;4(4):333-57.
51. United States Department of Labor. Bureau of Labor Statistics: Occupational Employment Statistics 2015. Available at https://www.bls.gov/oes/current/ oes211022.htm\#st (accessed 20 Dec 2016).

52. Miljkovic MD, Jones BL, Miller K. From the euthanasia society to physician orders for life-sustaining treatment: end-of-life care in the United States. The Cancer Journal. 2013;19(5):438-43.

53. Christ GH, Sormanti M. Advancing social work practice in end-of-life care. Soc Work Health Care. 1999;30(2):81-99.

54. Stein GL, Fineberg IC. Advance care planning in the USA and UK: a comparative analysis of policy, implementation and the social work role. $\mathrm{Br} J$ Soc Work. 2013;43(2):233-48.

55. Emanuel LL, Danis M, Pearlman RA, Singer PA. Advance care planning as a process - structuring the discussions in practice. J Am Geriatr Soc. 1995; 43(4):440-6.

56. Bern-Klug M, Gessert C, Forbes S. The need to revise assumptions about the end of life: implications for social work practice. Health \& Social Work. 2001;26(1):38-48.

57. Kass-Bartelmes BL, Hughes R. Advance care planning: preferences for care at the end of life. Journal of pain \& palliative care pharmacotherapy. 2004;18(1):87-109.

58. National End of Life Care Programme: Capacity, care planning and advance care planning in life limiting illness: A guide for health and social care staff. Leicester: National End of Life Care Programme. 2011. Available at: http:// www.ncpc.org.uk/sites/default/files/ACP_Booklet_June_2011.pdf (accessed 16 Jan 2017).

59. Bullock K. The influence of culture on end-of-life decision making J Soc Work End Life Palliat Care. 2011;7(1):83-98. 